\title{
Spreader Flap versus Spreader Graft in Dorsal Reconstruction following Hump Resection in Primary Closed Rhinoplasty
}

\author{
Original \\ Article \\ Mahmoud ElBestar, Mohamed Aly Abou-Zeid, Hisham Lasheen, Ahmed Farahat, \\ Mahmoud ElFouly, Mohamed. Sabaa, Ahmed ElSalmawy \\ Department of Otorhinolaryngology, Faculty of Medicine, Cairo University, Egypt
}

\begin{abstract}
Objectives: To evaluate outcome of spreader flaps versus the spreader grafts in reconstruction of the nasal dorsum after large hump resection. This includes both functional and aesthetic aspects.

Patients and Methods: Thirty patients seeking rhinoplasty for dorsal nasal hump. All surgeries were done through the closed approach. Patients were randomly divided into two groups and accordingly to the modality of nasal dorsal reconstruction after hump resection. Group (A) patients were scheduled for reconstruction using spreader grafts while in Group (B) spreader flaps were used. Evaluation included functional and aesthetic considerations. Functional subjective evaluation was done by Nasal Obstruction Symptom Evaluation (NOSE) score and objective assessment by active anterior rhinomanometry (AAR). Aesthetic evaluation included patients' assessment of their problem according to Visual Analogue scale (VAS) while objective evaluation was done based on a suggested scoring system designed by the authors using pre and post-operative photography. The evaluating surgeons were blinded regarding the vault reconstructive modality.

Results: In both groups significant improvement in both functional and aesthetic outcome - after a minimum of three months follow up- when comparing the pre and postoperative data that was obtained. There was no statistically significant difference in outcome between both groups.

Conclusion: The spreader flap is a good alternative to the spreader graft in nasal dorsal reconstruction after large hump resection giving similar positive results both functionally and aesthetically however, the authors find the autospreader flap more superior to spreader graft technique as it does not require cartilage harvest.
\end{abstract}

Key Words: Closed rhinoplasty, dorsal reconstruction, nasal hump, spreader flap, spreader graft.

Received: 25 July 2020, Accepted: 28 July 2020.

Corresponding Author: Mohamed Aly Abou-Zeid, MD, Department of Otorhinolaryngology, Faculty of Medicine, Cairo University, Egypt. Tel.: 002-01003302730,E-mail: morakab@gmail.com

ISSN: 2090-0740, November 2020 Vol.21, No.3.

\section{INTRODUCTION}

A dorsal nasal hump is one of the main indications for rhinoplasty that maybe inherited or post-traumatic. The skeletal framework of the hump may constitute cartilaginous, bony or both components ${ }^{[1]}$.

Dorsal hump resection results in removal of a critical part of the Osseo-cartilaginous dorsum which necessitates mid-vault reconstruction ${ }^{[2]}$. The bony dorsum is simply reconstructed first by inward fracture of the nasal bones ${ }^{[3]}$, however, the cartilaginous dorsum must be reconstructed in a way to prevent bony cartilaginous disjunction otherwise an inverted-V deformity may occur. Reconstruction should maintain an open nasal valve to prevent mid-vault insufficiency and internal nasal valve (INV) collapse ${ }^{[2]}$.

In order to increase the INV angle, a spacer has to be placed between the upper lateral cartilages (ULCs) and the septum to stabilize and shift the ULCs away from the dorsal septum1.
In 1984, Sheen introduced the spreader graft as a method of reconstruction of the nasal dorsum and recommended that it should be used for all primary rhinoplasty cases where resection of the upper cartilaginous vault was part of the surgical plan for obtaining eyebrow-tip aesthetic lines and maintaining INV function ${ }^{[4]}$.

The spreader flap technique emerged during the 1990s, its principle entailed that the upper lateral cartilages are not resected during humpectomy, but separated from the septum, mobilized, and then rotated into the area of the $\mathrm{INVS}^{[5]}$. Its given name evolved from "upper lateral cartilage bending" by Seyhan in $1997^{[6]}$ to the "Lapel technique" a year later by Lerma ${ }^{[7]}$ however in the same year Oneal and Berkowitz gave it its current name; spreader flaps ${ }^{[8]}$.

Although spreader grafts are considered the gold standard for reconstructing the middle one-third of the nose, spreader flaps can invariably be created and act as a substitute for the spreader grafts $^{[9]}$. The spreader flap 
minimizes the need for harvesting additional material. Also, because scoring has been minimized or eliminated from the old spreader flap technique, it is possible to use the spreader flap in almost all rhinoplasty cases that involve resection of a hump larger than $3 \mathrm{~mm}^{[10]}$.

This study compares between Spreader graft and flap techniques regarding the functional and aesthetic outcome in primary closed rhinoplasty after dorsal humpectomy. It also addresses some technical considerations related to the feasibility of performed middle vault reconstruction via the closed rhinoplasty approach.

\section{PATIENTS AND METHODS:}

This is a randomized comparative trial that included thirty patients seeking rhinoplasty for dorsal nasal hump. Patients presented and were operated upon at the Otolaryngology Department in a university hospital during the period from August 2016 to May 2018.

Thirteen patients were males and 17 were females. The only inclusion criterion was significant dorsal nasal hump larger than $3 \mathrm{~mm}$ that will require reconstruction of the cartilaginous vault after hump resection while exclusion criteria included: age less than 18 years, previous attempts of rhinoplasty, and history of recent nasal trauma.

Patients were randomly divided using sealed envelopes (1:1 allocation) into two groups and accordingly the modality of reconstruction of the nasal dorsum after hump resection. Group (A) patients were scheduled for reconstruction using spreader grafts. Group (B) patients were scheduled for reconstruction using spreader flaps.

The principles of the 1975 Declaration of Helsinki were followed in this study. All patients provided their written informed consent before their operations. The study was approved by the scientific and ethical committee of our institution.

\section{Patients were subjected to preoperative functional and aesthetic assessment as follows:}

Subjective functional evaluation was performed using the Nasal Obstruction Symptom Evaluation scoring system (NOSE) proposed by Stewart et al., 2004 ${ }^{[11]}$. This scoring system is based on asking the patient five questions regarding the nasal patency. The scale ranges from 0 (no problem) to 4 (severe problem). All patients were helped by a visual analogue for precise answers. The final result was obtained by multiplying the raw score by 5 to obtain a score from 100. Thus, a higher score indicated worse symptoms.

Objective functional evaluation was done using Active Anterior Rhinomanometry (AAR) carried out by the same investigator. This was standardly done after 15 minutes patient seated comfortably on a chair and then 5 minutes after decongestion with xylometazoline $0.1 \%$. Nasal airflow was measured using a face mask that is large enough so that it does not distort the external nasal structures. The nasal airflow was measured by the RhinomanometerNR7D; (Mercury electronics Scotland Ltd., Glasgow, UK).

Pre-operative photography was obtained for all patients; this included a set of six photos taken from different angles (portrait, basal, bilateral profile and $3 / 4$ oblique views).

All candidates underwent rhinoplasty by the same surgeon using the "closed" technique. The dorsum was approached using bilateral inter-cartilaginous incisions or infra-cartilaginous incisions and the septum through a left hemi-transfixion incision.

Patients in group (A) had their dorsum reconstructed by spreader grafts obtained from the nasal septal cartilage, measuring $1.5-2 \mathrm{~cm}$ length by $3-5 \mathrm{~mm}$ width and $1.5-2 \mathrm{~mm}$ thickness (Figure $1 \mathrm{a}$ ). A pocket was dissected at each side of the septum (Figure 1b, c) to allow for spreader graft insertion between the septum and the upper lateral cartilage (Figure 1d) and fixed in place using 5/0 Proline mattress sutures. Then the upper lateral cartilages were sutured on both sides traversing both spreader grafts and the septum by at least 2 transverse mattress sutures, with the first suture taken layer by layer while the next ones traversed through the layers with straightening of the needle (Figure 1e). Excess cartilage was trimmed off the ULCs.

Patients in group (B) had their dorsum reconstructed using spreader flaps. The upper lateral cartilages were dissected and separated from the septum (Figure 2a). In order to reduce the dorsal aspect of the septum, the mucoperichondrium has to be dissected. Dissecting the medial-most ends of the ULCs can then be performed to facilitate their infolding. This was performed through the inter-cartilaginous incision or through an infracartilaginous (rim) incision and delivery approach if tip surgery was needed and planned from the start of the operation for better exposure. The excess upper lateral cartilage after hump resection was then folded to form 2 layers, the medial one acting as an autospreader flap (Figure 2b). After folding the upper lateral cartilage two $5 / 0$ prolene transverse mattress sutures were taken from the ipsilateral nostril (Figure 2c-f). At least 1 transverse mattress suture was then taken between the two upper laterals, the spreader flaps and the septum while straightening the cutting needle on $5 / 0$ prolene (Figure $2 \mathrm{~g}$ ).

Follow-up ranged from 3 to 17 months with a mean of 7 months. Postoperative assessment included both functional and aesthetic outcomes. Functional assessment was subjectively and objectively performed in a way similar to the preoperative assessment. 
Aesthetic outcome was assessed by both the patient and three blinded investigator surgeons. Patients expressed their satisfaction using a VAS-aided questionnaire ranging from 0 to 4 where 0 meant unsatisfied and 4 meant totally satisfied by the shape of his/her nose. Preoperative and postoperative photographs from the different views were projected in front of the investigator surgeons. Five criteria were included: Brow-tip line, width of the middle third, noticeable inverted- $\mathrm{V}$, noticeable irregularity and overall outcome of surgery. Each criterion is scored from 0-2 where 0 means bad aesthetic outcome, 1 partial improvement and 2 is excellent. A score ranging from $0-10$ was obtained, where 0 means no improvement and 10 means excellent results. The mean of the three surgeons is then used as the final value.

All the results were tabulated and statistically analyzed using Microsoft excel 2007 and SPSS 16 for Windows. Data was summarized using mean and standard deviation. Wilcoxon test was used to analyze preoperative and postoperative values of NOSE scores and VAS scores within each group while Mann-Whitney $U$ test was used for comparison between both groups. Paired sample t-test was used to analyze the values of preoperative and postoperative values of the AAR within each group while independent sample t-test was used to compare both groups. $P$-value of $>0.05$ was considered statistically significant.

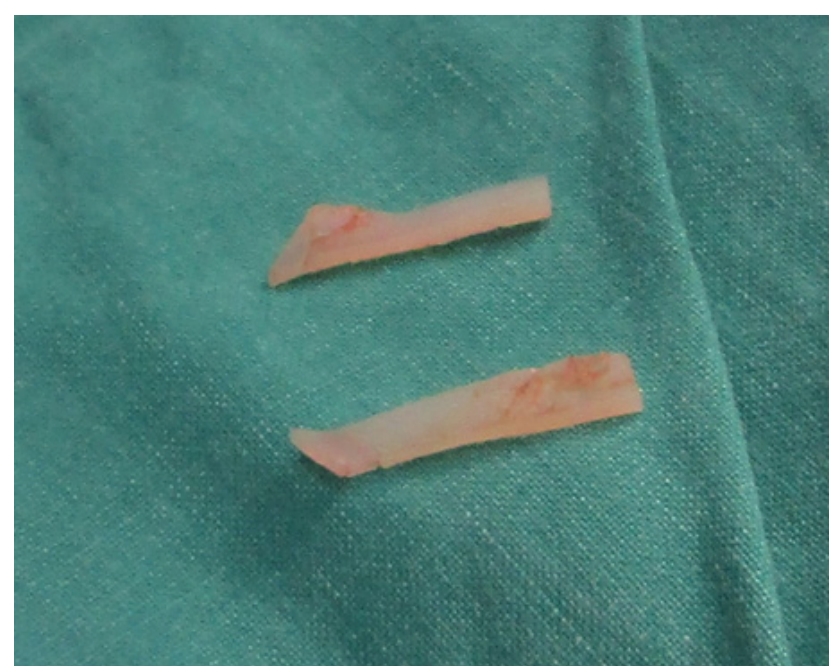

Fig 1a: Spreader grafts harvested from nasal septum

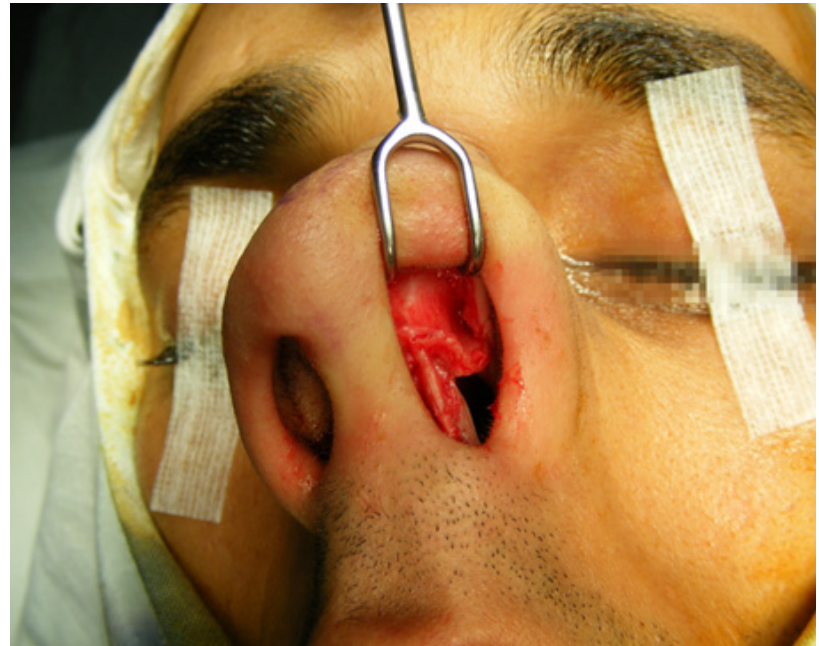

Fig 1b: $\mathrm{K}$ area exposed through closed approach - intercartilaginous incision

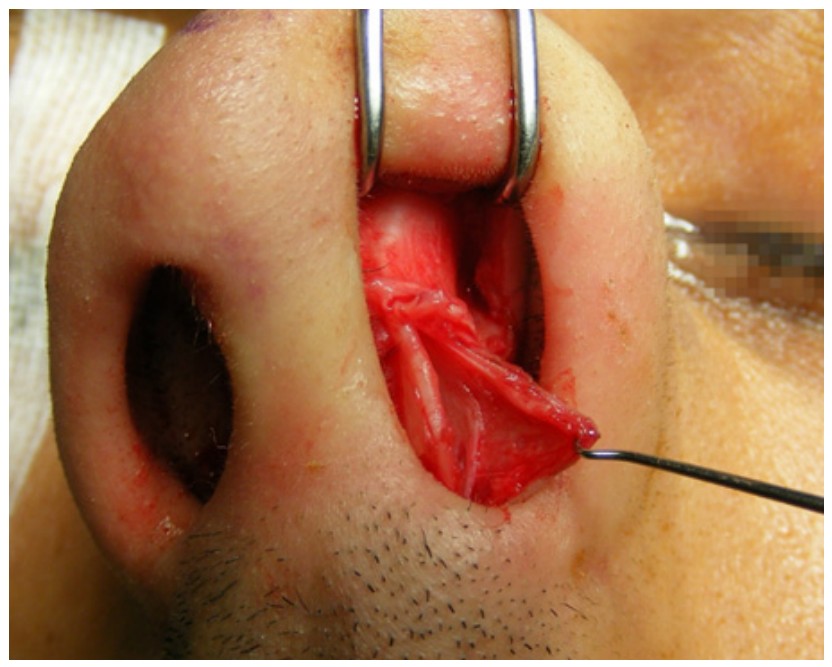

Fig 1c: Dissection of pocket for spreader graft insertion

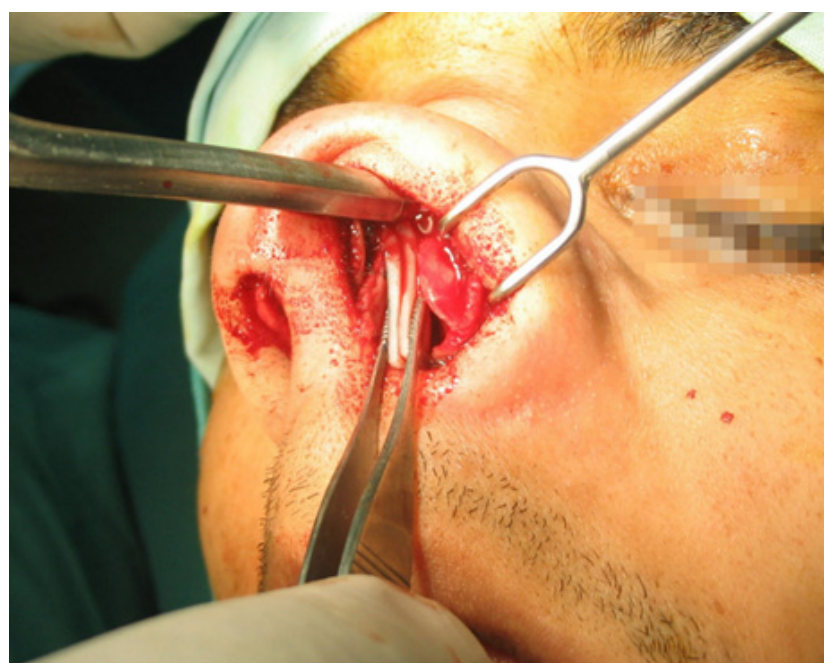

Fig 1d: Insertion of spreader graft between septum and left ULC 


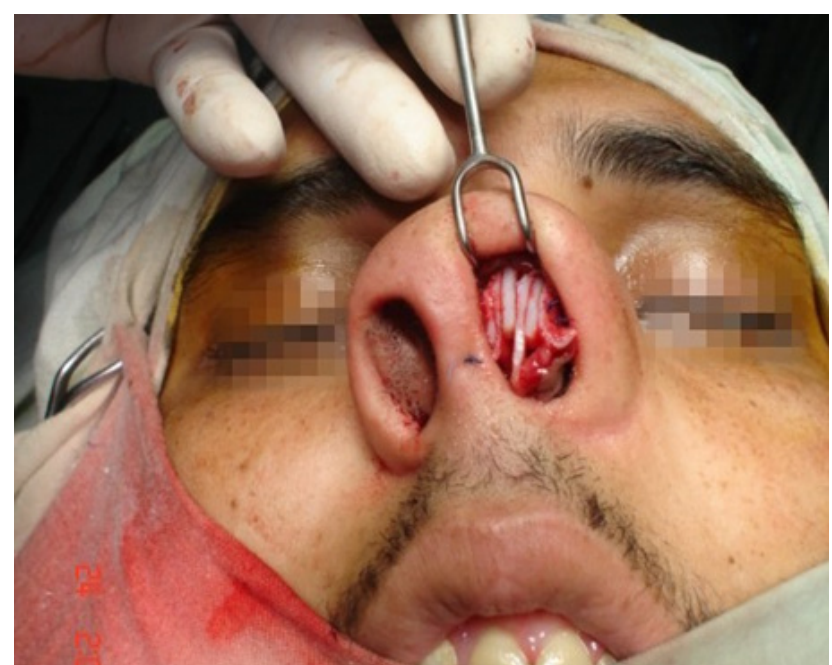

Fig 1e: Spreader Grafts kept in place by $5 / 0$ prolene sutures through inter-cartilaginous incisions

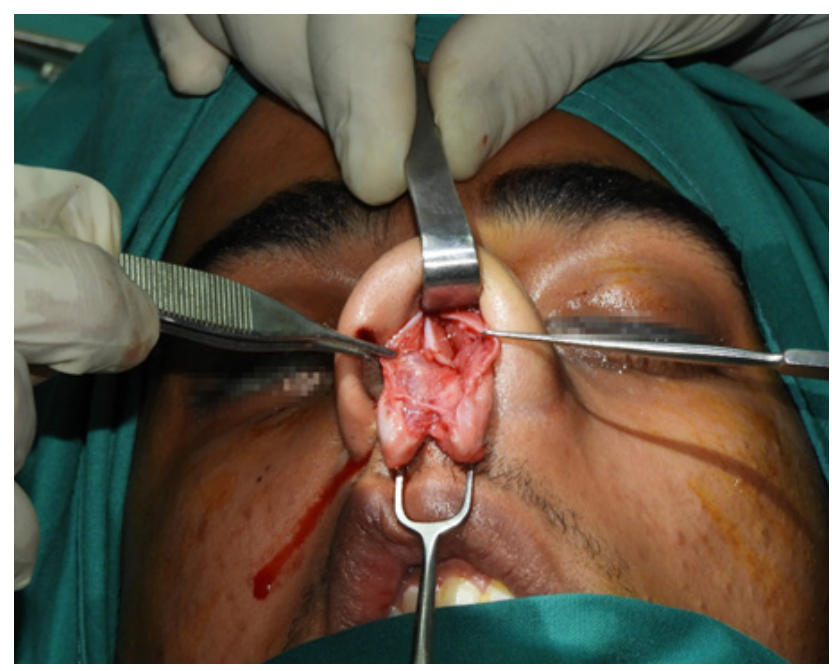

Fig 2a: ULCs dissected and separated from the septum through closed approach - infra-cartilaginous incisions

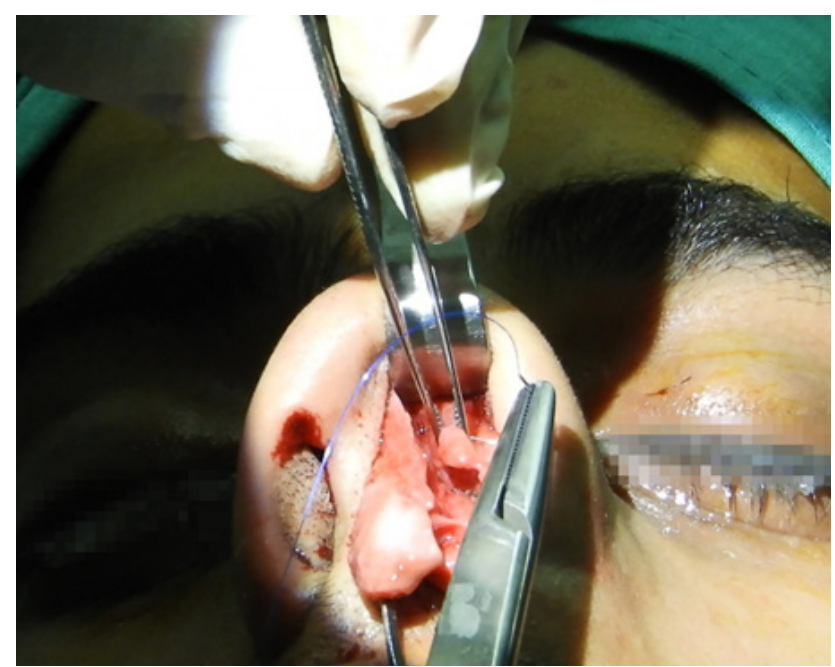

Fig 2b: The left ULC folded for the medial part to act as the spreader flap

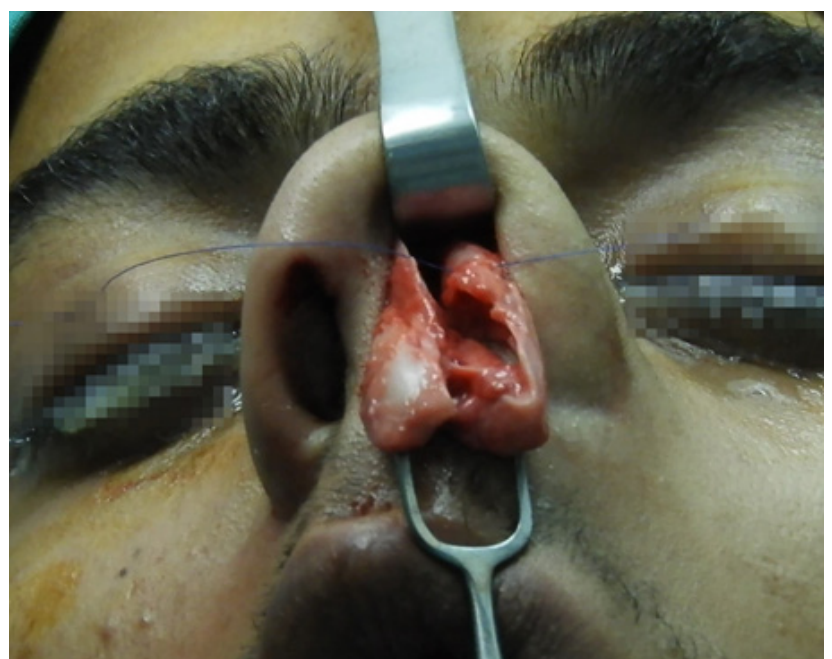

Fig 2c: First suture taken through left ULC

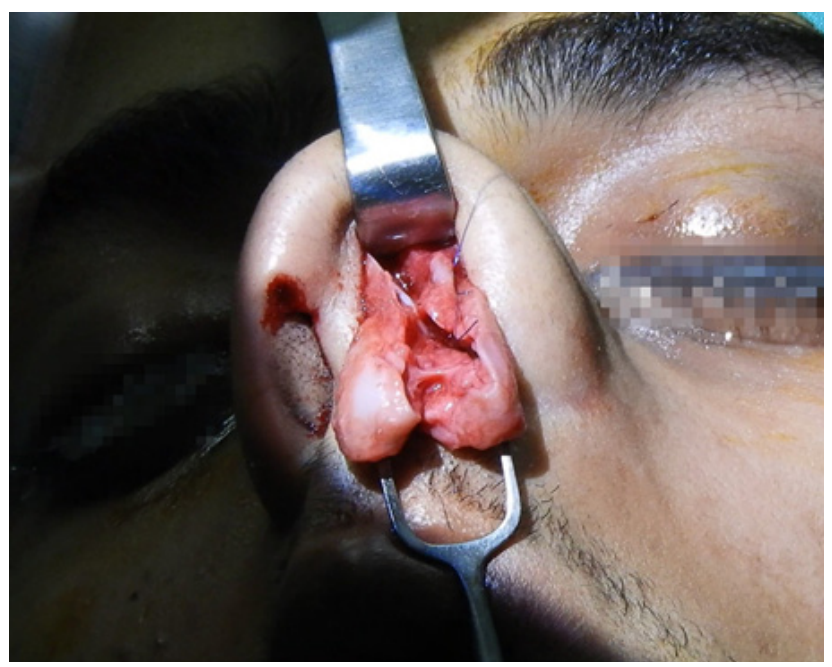

Fig 2d: Second mattress suture taken through left ULC

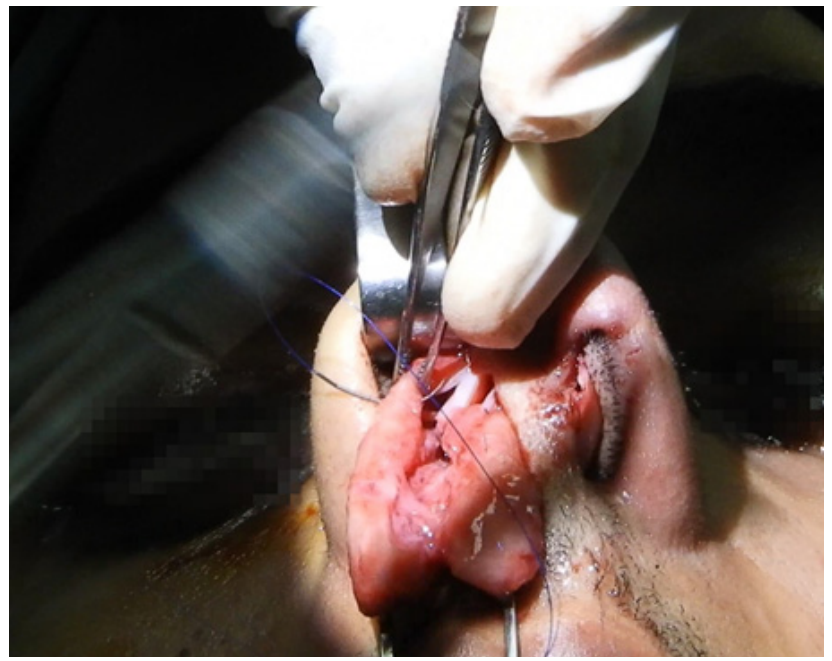

Fig 2e: First suture taken in the right ULC through right nostril 


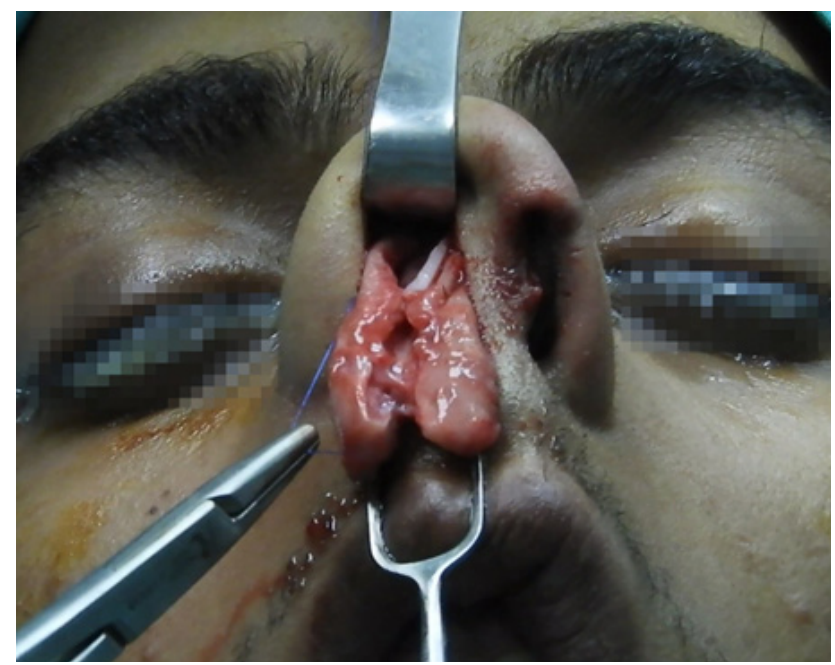

Fig 2f: Two mattress sutures to fold both ULCs to act as spreader flaps

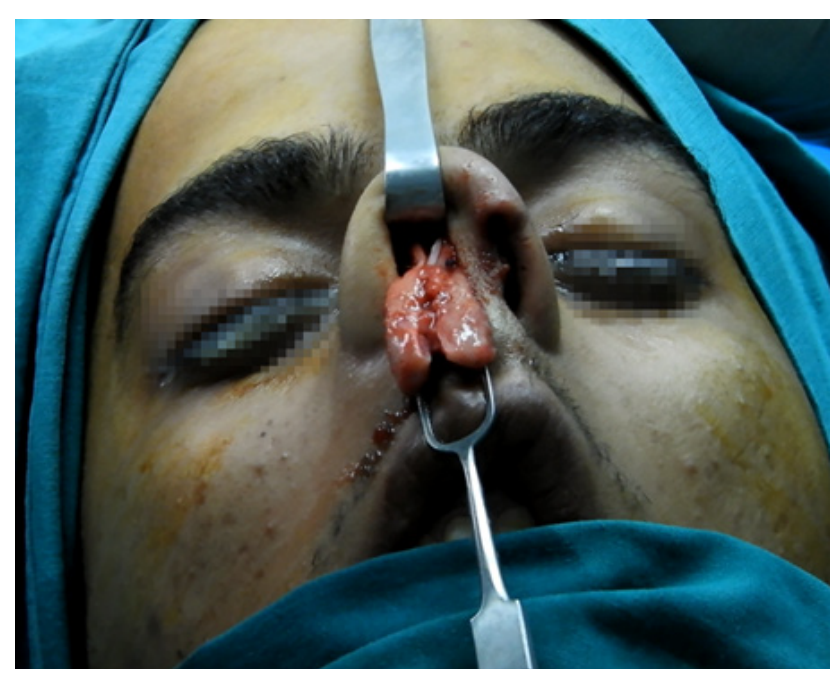

Fig 2g: Spreader Flaps kept in place by 5/0 prolene sutures fixed to the septum through infra-cartilaginous incisions

\section{RESULTS:}

In the 30 patients constituting the sample 13 were males and 17 were females. Ages ranged between 18 and 33 years with a mean age of 25.1 years \pm 4.9 . Regarding the cause of the nasal hump 18 of our patients $(60 \%)$ gave history of nasal trauma while 12 of our patients $(40 \%)$ had inherited hump.

The gender and age distribution were not found to have a significant difference between the groups with the p-value of 0.713 and 0.774 respectively $(P>.05)$ as measured by Fischer's exact test and independent sample t-test respectively.

Analysis of the NOSE score for subjective evaluation of the nasal function was done using Wilcoxon test. Group
A showed significant improvement in the postoperative scores compared with the preoperative ones. The mean NOSE score preoperatively was $52.67 \pm 30.3$; while postoperatively, it was $20.33 \pm 14.2$, $(P$ value $=0.002)$. Group B also showed significant improvement in the postoperative scores compared with the preoperative ones, $(P$ value $=0.001)$. The mean NOSE score preoperatively was $55.36 \pm 22.1$; while postoperatively it was $23.21 \pm 14.7$. When comparing group A with B neither groups showed superiority in improving the nasal function subjectively when measured by Mann-Whitney $U$ test the p-value was 0.662. (Table 1).

Objective evaluation of the nasal function was done by AAR. Group A patients showed that the mean nasal resistance preoperatively decreased from $0.506 \mathrm{~Pa} / \mathrm{mL} /$ sec to $0.224 \mathrm{~Pa} / \mathrm{mL} / \mathrm{sec}$ during inspiration and from 0.484 $\mathrm{Pa} / \mathrm{mL} / \mathrm{sec}$ to $0.23 \mathrm{~Pa} / \mathrm{mL} / \mathrm{sec}$ during expiration. This difference was found to be significant by paired sample t-test $(P$ value $=0.005$ and 0.007 respectively $)$. Group $\mathrm{B}$ patients also showed that the mean nasal resistance preoperatively decreased from $0.516 \mathrm{~Pa} / \mathrm{mL} / \mathrm{sec}$ to $0.216 \mathrm{~Pa} / \mathrm{mL} / \mathrm{sec}$ during inspiration and from $0.495 \mathrm{~Pa} / \mathrm{mL} /$ sec to $0.233 \mathrm{~Pa} / \mathrm{mL} / \mathrm{sec}$ during expiration which was found to be significant by paired sample t-test $(P$ value $=0.004$ and 0.004 respectively). When comparing group (A) with group (B) by independent sample t-test, the improvement of nasal function as measured objectively by AAR was found to be statistically insignificant $(p>.05)$ whether the dorsum was constructed by spreader grafts or flaps with a p-value of 0.881 and 0.947 for inspiration and expiration respectively. (Table 1 ).

Patients' satisfaction scores for the aesthetic outcome was analyzed using Wilcoxon test. Group A showed significant improvement in the patient's satisfaction regarding the aesthetic results within group A giving a mean VAS of $2.87 \pm 0.64$ instead of $0.60 \pm 0.74$. Group $B$ also showed significant improvement in the patient's satisfaction regarding the aesthetic results within group A giving a mean VAS of $3.07 \pm 0.70$ instead of 0.57 \pm 0.64 . When comparing group A with B Analyzing the improvement in postoperative patients' ${ }^{6}$ satisfaction scores measured by VAS, it was found that there is no statistically significant difference between the improvement in the values between both groups $(p>0.05)$ when measured by Mann-Whitney U test the p-value was 0.565. (Table 1).

The scores of blinded surgeon's evaluation of aesthetic outcome obtained from both groups based on pre and postoperative photography (Figures 3-8), although was slightly higher in group B $7.64 \pm 1.1$ than group A $7.33 \pm 1.2$ but this was not statistically significant ( $p$-value $>0.05$ ) when analyzed by Mann Whitney $U$ test with a p-value of 0.464. (Table 1). 
Table 1: Pre and Postoperative results of both groups and comparison of improvement between both groups

\begin{tabular}{|c|c|c|c|c|c|c|c|}
\hline \multirow[t]{2}{*}{$($ Mean $\pm \mathrm{SD})$} & \multicolumn{3}{|c|}{ Group A (Spreader Grafts) } & \multicolumn{3}{|c|}{ Group B (Spreader Flaps) } & \multirow{2}{*}{$\begin{array}{l}\begin{array}{l}\text { Comparison } \\
\text { between both } \\
\text { groups }\end{array} \\
\text { P value }\end{array}$} \\
\hline & Pre operative & Post operative & $\begin{array}{l}P \text { value } \\
\text { between Pre } \\
\text { and Post }\end{array}$ & Pre operative & Post operative & $\begin{array}{l}P \text { value } \\
\text { between Pre } \\
\text { and Post }\end{array}$ & \\
\hline NOSE & $52.67 \pm 30.35$ & $20.33 \pm 14.20$ & 0.002 & $55.36 \pm 22.09$ & $23.21 \pm 14.74$ & 0.001 & 0.662 \\
\hline $\begin{array}{l}\text { AAR } \\
\text { inspiration }\end{array}$ & $0.506 \pm 0.32$ & $0.224 \pm 0.09$ & 0.005 & $0.516 \pm 0.39$ & $0.216 \pm 0.29$ & 0.004 & 0.881 \\
\hline $\begin{array}{l}\text { AAR } \\
\text { Expiration }\end{array}$ & $0.484 \pm 0.29$ & $0.230 \pm 0.07$ & 0.007 & $0.495 \pm 0.07$ & $0.233 \pm 0.07$ & 0.004 & 0.947 \\
\hline VAS & $0.60 \pm 0.74$ & $2.87 \pm 0.64$ & 0.001 & $0.57 \pm 0.64$ & $3.07 \pm 0.70$ & 0.001 & 0.565 \\
\hline $\begin{array}{l}\text { Esthetic } \\
\text { Outcome } \\
\text { by blinded } \\
\text { surgeons }\end{array}$ & & $7.33 \pm 1.2$ & & & $7.64 \pm 1.1$ & & 0.464 \\
\hline
\end{tabular}
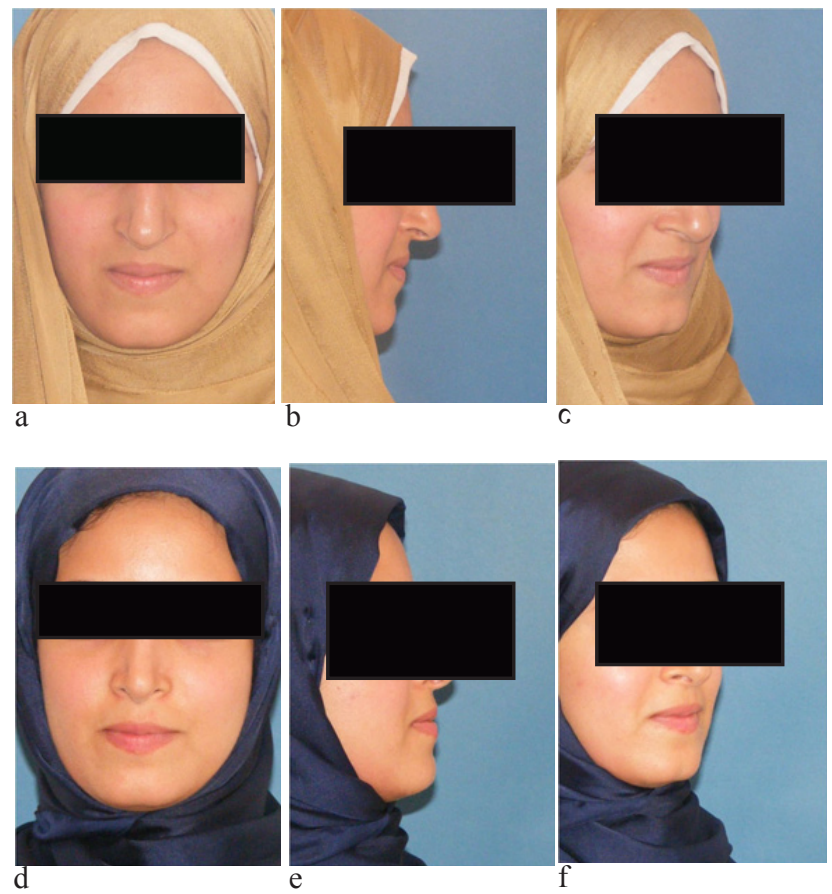

Fig 3: A 22 year old female with inherited nasal dorsal hump. In addition she had an ill defined tip. She was included in Group (A). She had her dorsum reconstructed by spreader grafts. Ancillary steps included tip definition. These are the preoperative ( $\mathrm{a}, \mathrm{b}$ and c) and 6 months postoperative photos (d, e and f). Functionally she had improvement on both subjective and objective assessment. She scored her aesthetic outcome as 3. Peer review of her photos had an average score of 9 .
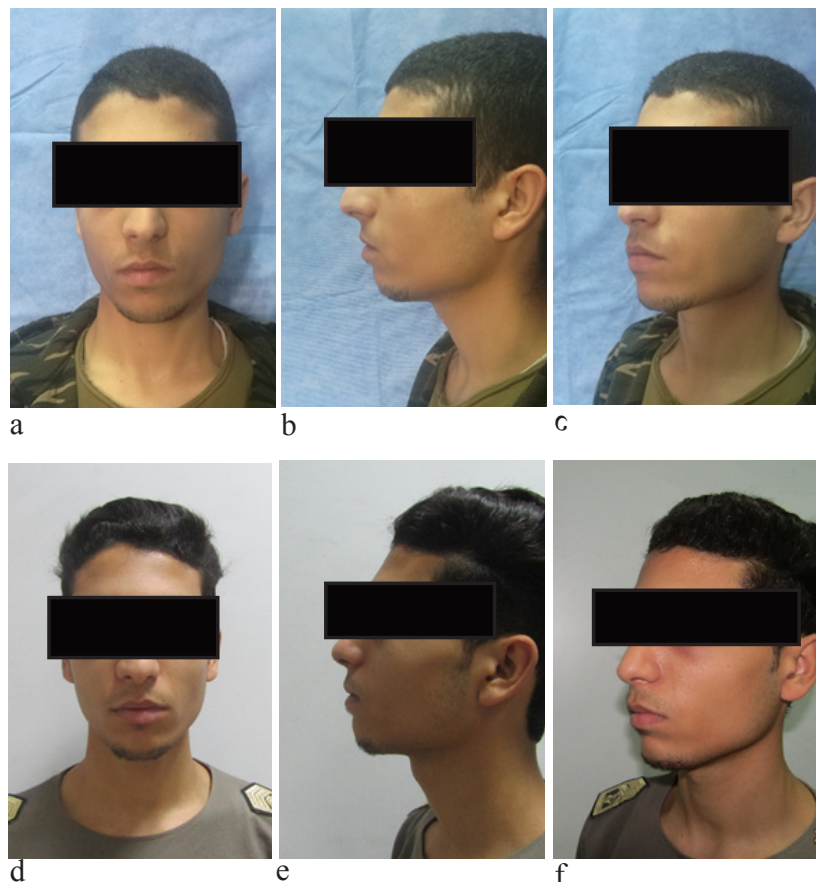

Fig 4: An 18 year old male patient with post-traumatic nasal hump. In addition he had deviated dorsum and septal deviation. He was included in group (A). His nasal dorsum was reconstructed by spreader grafts. These are the preoperative $(\mathrm{a}, \mathrm{b} \& \mathrm{c})$ and 3 months postoperative photos (d, e \& f). Functionally he had improvement on both subjective and objective assessment. He scored his aesthetic outcome as 3 . Peer review of his photos had an average score of 8.67 . 

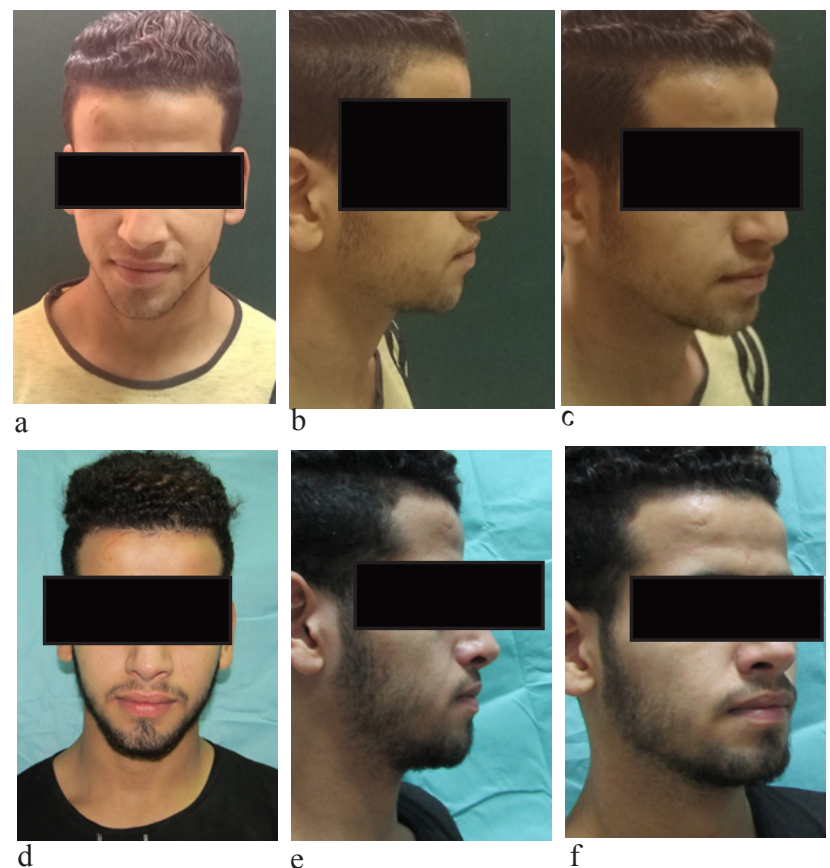

Fig 5: A 19 year old male patient with post-traumatic nasal hump. In addition he had deviated dorsum and septal deviation and dislocation. He was included in group (A). His nasal dorsum was reconstructed by spreader grafts. Ancillary steps included tip projection and repair of his fractured dislocated septum. Functionally he had improvement on both subjective and objective assessment. He scored his aesthetic outcome as 4. Peer review of his photos had an average score of 8.67. (a, b \& c preoperative photos while $\mathrm{d}$, e \& $\mathrm{f}$ are the 11 months post-operative ones).
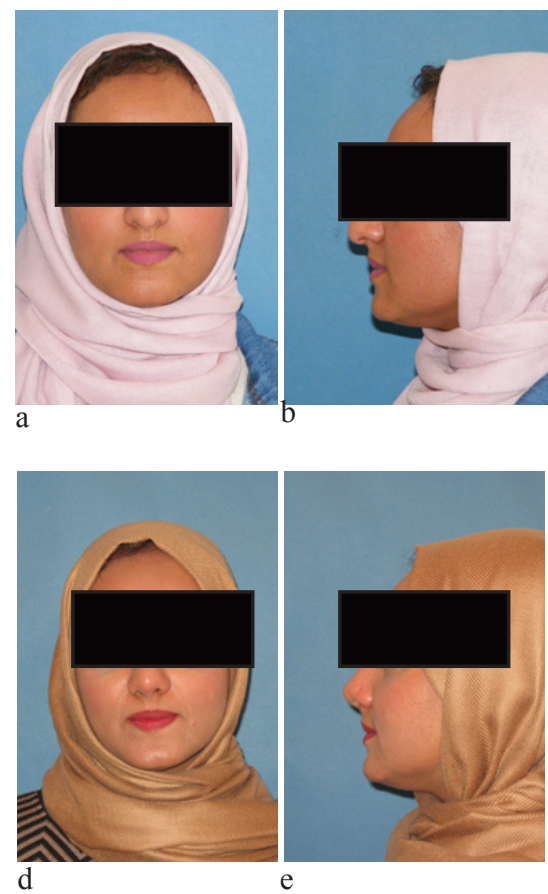

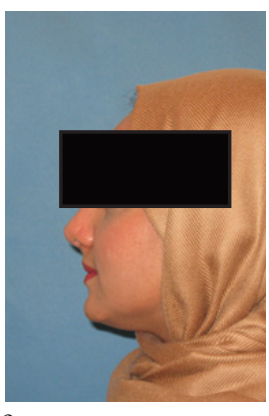

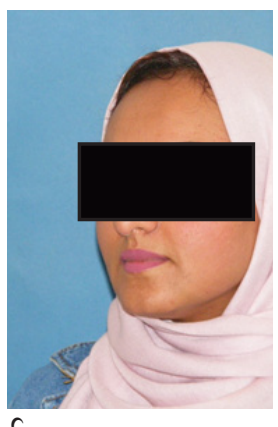

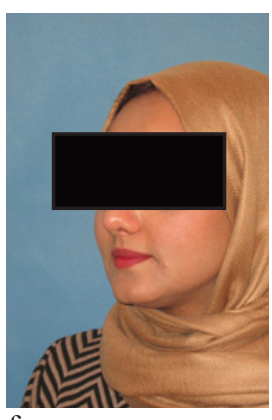

f
Fig 6: A 25 year old female with inherited hump. She was included in Group (B). underwent hump resection with reconstruction of nasal dorsum using spreader flaps. Ancillary steps included tip definition. These are the preoperative $(\mathrm{a}, \mathrm{b}$ and $\mathrm{c})$ and 7 months postoperative photos (d, e and f). Functionally she had improvement on both subjective and objective assessment. She scored her aesthetic outcome as 3. Peer review of her photos had an average score of 9.33

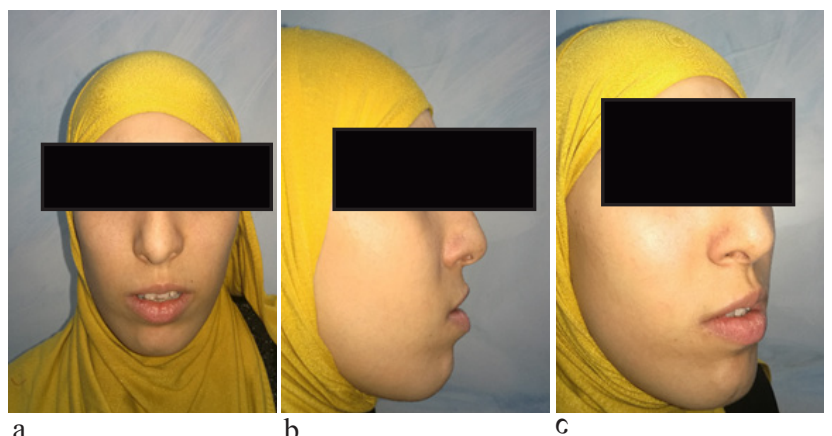

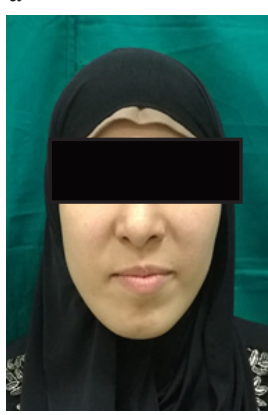

d

Fig 7: An 18 year old female with inherited nasal dorsal hump. In addition she had an ill defined tip. She was included in Group (B) She had her dorsum reconstructed by spreader flaps. Ancillary steps included tip definition. These are the preoperative $(\mathrm{a}, \mathrm{b}$ and $\mathrm{c})$ and 10 months postoperative photos (d, e and f). Functionally she had improvement on both subjective and objective assessment She scored her aesthetic outcome as 3. Peer review of her photos had an average score of 9 .
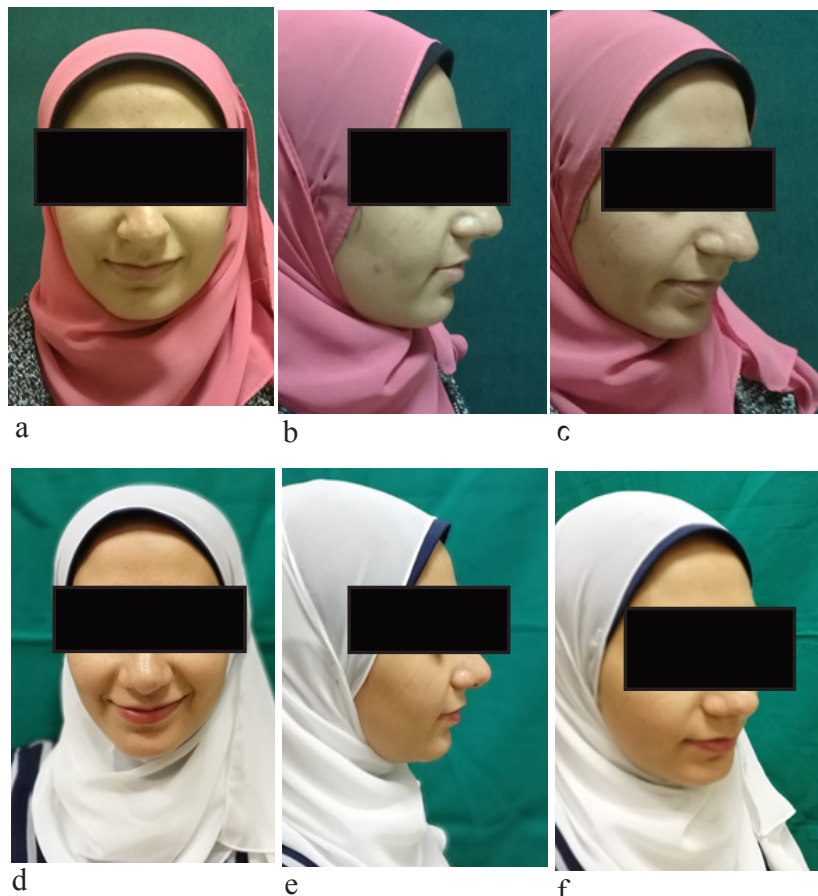

Fig 8: A 22 year old female with inherited nasal dorsal hump. In addition she had a deviated nose and an ill defined droopy tip. She was included in Group (B). She had her dorsum reconstructed by spreader flaps. Ancillary steps included tip reduction, projection and definition. These are the preoperative ( $a, b$ and $c$ ) and 3 month postoperative photos (d, e and f). Functionally she had very slight improvement on both subjective and objective assessment (more or less the same). She scored her aesthetic outcome as 3. Peer review of her photos had an average score of 9 


\section{DISCUSSION}

In moderate and severe humps, reconstruction of the middle vault after humpectomy is deemed mandatory ${ }^{[12]}$. Simple assembly of the trimmed edges of the upper lateral cartilages with the septum can end up with unsatisfactory functional and aesthetic outcome. Failure to reproduce the natural angle between the wide dorsal edge of the septum and the edges of the two upper lateral cartilages can cause considerable nasal obstruction. In addition, a visible inverted V-shaped deformity can occur due to medial collapse of the cartilage leaving visible bony edges ${ }^{[2]}$. Reconstruction of the middle vault can be done by placing a "spacer", or "spreader" that pushes the edges of the upper lateral cartilages laterally against the bone ${ }^{[1,12]}$.

The first designed spreader was a cartilage graft placed on either side of the dorsal septal edge. These grafts can be placed in closed pockets ${ }^{[4]}$ or placed in an open field and fixed using mattress sutures ${ }^{[3]}$.

Then the use of the excess edges of the upper laterals as turn-in flaps has been introduced. The recoil of the turned in flaps help achieve the same objective. Spreader flaps, however, have to be fixed by mattress sutures $^{[10]}$.

While both spreader grafts and flaps can achieve the same goals, each has its pros and cons. Grafts can provide different designs and volumes to achieve the desired objective. In addition it can be introduced into tight pockets created on either side of the dorsal septum without fixation ${ }^{[3]}$. However, adequate material is needed to design such grafts. On the other hand, flaps provide limited volume determined by the thickness of the dorsal edges of the upper lateral cartilages. Furthermore, flaps need to be fixed in place using sutures. However, their use spares the excess cartilage that is otherwise trimmed, and consequently spare the need for graft material ${ }^{[13]}$.

This study was designed to address two questions related to middle vault reconstruction. The first question is: can the spreader flaps, with its limited volume, produce the same functional and aesthetic outcome of the grafts? The second question is: what is the technical feasibility of fixing the grafts and the flaps using mattress sutures through a closed approach?

By comparing the functional outcome subjectively and objectively, there was no significant difference between spreader grafts and flaps.

Subjective assessment is commonly done using the NOSE score ${ }^{[11]}$. De Pochat et al. (2012) and Standlee and Hohman (2017) reported improvement in NOSE scores for patients who had spreader grafts. ${ }^{[14,15]}$ Yoo and Most (2011), Eren et al. (2014) and Huseein et al. (2015) reported similar improvement with spreader flaps ${ }^{[2,16,17]}$ Simpler scoring systems were used by other authors for subjective assessment. Saedi et al. (2014) and Hassanpour et al. (2016) used simple questionnaires and compared between the functional outcomes of spreader grafts and flaps ${ }^{[18,19]}$. They reported no significant differences between both techniques.

Objective functional assessment was performed using AAR. Our results showed improvement in airflow in both groups with no significant difference between both. Boccieri et al. (2005) and de Pochat et al. (2012) reported objective improvement after the use of spreader grafts ${ }^{[14,20]}$. Eren et al. (2014) reported same results with the use of spreader flaps 2.Hassanpour et al. (2016) used AAR to compare between the outcome of grafts and flaps and reported no significant difference between both ${ }^{[18]}$.

The aesthetic outcome of spreaders is usually measured by patient satisfaction. Eren et al. (2014), Saiedi et al. (2014) and AlRubaiee and AlKamil (2016) reported improvement in the aesthetic outcome after the use of spreader flaps ${ }^{[2,13,19]}$. Hassanpour et al. (2016) reported no significant difference between the aesthetic outcome of spreader grafts and flaps ${ }^{[18]}$. Their findings are similar to ours. In addition, we used another parameter to assess the aesthetic outcome, which is the peer review. Surgeons, blinded to the reconstructive modality, reported slightly higher scores for spreader flaps, but this proved to be statistically insignificant. When comparing the scores of different surgeons for each patient, the scores were found to be more or less similar, indicating the reliability of the scoring system.

Therefore, by comparing the functional outcome subjectively and objectively as well as the aesthetic outcome using patient satisfaction and peer review, there was no significant difference between spreader grafts and flaps. These results may encourage the utilization of the excess upper lateral cartilage in reconstruction and obviate the need for graft material in primary rhinoplasty. For closed approach rhinoplasty surgeons, spreader grafts can be introduced through tight pockets. However, the use of spreader flaps, with mandatory suture fixation, may pose a significant surgical challenge. Gruber et al. (2011) described the difficulty in fixing the spreader flaps as a pain shaking effort, akin to building a ship in a glass bottle. This particularly applies to the cephalic-most sutures ${ }^{[10]}$.

In this study, all spreader flaps were performed via the closed approach. It has to be admitted that fixation 
of the five layers, especially along the cephalic border needed more time and experience, however with proper exposure of the dorsum by inter-cartilaginous incisions, it can be safely done without much struggle.

Every study has limitations. The authors used the available rhinomanometry, given that it is the only quantifiable objective measure of nasal function currently available $e^{[21]}$, to measure nasal function objectively. However, they recommend that further studies can additionally use acoustic rhinometry which can locate the site of obstruction if internal nasal valve collapse is encountered. It can also be recommended that further studies with larger sample size and longer term follow up are conducted to evaluate the long term effect of dorsal reconstruction in opposing scar contracture and maintaining proper middle third contour.

\section{CONCLUSION}

Based on the results of the study, spreader flaps can be recommended as the first choice in middle vault reconstruction, sparing the need for cartilage grafts. Spreader flaps provide similar functional and aesthetic results as compared to spreader flaps and can efficiently restore the integrity of the middle vault after hump resection. The closed approach needs more effort and hence experience in fixing the spreader flaps in place, however, with minor technique refinements, it can be certainly reproducible.

\section{CONFLICT OF INTEREST}

There are no conflicts of interest.

\section{REFERENCES}

1. Teymoortash A, Fasunla JA, Sazgar AA. The value of spreader grafts in rhinoplasty: a critical review. European archives of oto-rhino-laryngology : official journal of the European Federation of Oto-RhinoLaryngological Societies. May 2012;269(5):14111416.

2. Eren SB, Tugrul S, Ozucer B, Meric A, Ozturan O. Autospreading spring flap technique for reconstruction of the middle vault. Aesthetic plastic surgery. Apr 2014;38(2):322-328.

3. Apaydin F. Rebuilding the Middle Vault in Rhinoplasty: A New Classification of Spreader Flaps/Grafts. Facial plastic surgery : FPS. Dec 2016;32(6):638-645.

4. Sheen JH. Spreader graft: a method of reconstructing the roof of the middle nasal vault following rhinoplasty. Plastic and reconstructive surgery. Feb 1984;73(2):230-239.
5. Wurm J, Kovacevic M. A new classification of spreader flap techniques. Facial plastic surgery : FPS. Dec 2013;29(6):506-514.

6. Seyhan A. Method for middle vault reconstruction in primary rhinoplasty: upper lateral cartilage bending. Plastic and reconstructive surgery. Dec 1997;100(7):1941-1943.

7. Lerma J. The "lapel" technique. Plastic and reconstructive surgery. Nov 1998;102(6):2274-2275.

8. Oneal RM, Berkowitz RL. Upper Lateral Cartilage Spreader Flaps in Rhinoplasty. Aesthetic surgery journal. 1998;18(5):370-371.

9. Gruber RP, Perkins SW. Humpectomy and spreader flaps. Clinics in plastic surgery. Apr 2010;37(2):285291.

10. Gruber RP, Melkun ET, Woodward JF, Perkins SW Dorsal reduction and spreader flaps. Aesthetic surgery journal. May 2011;31(4):456-464.

11. Stewart MG, Witsell DL, Smith TL, Weaver EM, Yueh B, Hannley MT. Development and validation of the Nasal Obstruction Symptom Evaluation (NOSE) scale. Otolaryngology--head and neck surgery : official journal of American Academy of OtolaryngologyHead and Neck Surgery. Feb 2004;130(2):157-163.

12. Kovacevic M, Riedel F, Göksel A, Wurm J. Options for middle vault and dorsum restoration after hump removal in primary rhinoplasty. Facial Plastic Surgery. 2016;32(04):374-383.

13. Alrubaiee A, Alkamil KW. the effect of spreader flap in reconstruction of the middle vault of the nose after humpectomy. Bas J Surg, June, 22, 2016. 2016( June, 22, 2016):60-65

14. de Pochat VD, Alonso N, Mendes RR, Cunha MS, Menezes JV. Nasal patency after open rhinoplasty with spreader grafts. Journal of plastic, reconstructive $\&$ aesthetic surgery : JPRAS. Jun 2012;65(6):732-738

15. Standlee AG, Hohman MH. Evaluating the Effect of Spreader Grafting on Nasal Obstruction Using the NOSE Scale. The Annals of otology, rhinology, and laryngology. Mar 2017;126(3):219-223.

16. Yoo S, Most SP. Nasal airway preservation using the autospreader technique: analysis of outcomes using a disease-specific quality-of-life instrument. Archives of facial plastic surgery. Jul-Aug 2011;13(4):231-233. 
17. Hussein WK, Elwany S, Montaser M. Modified autospreader flap for nasal valve support: utilizing the spring effect of the upper lateral cartilage. European archives of oto-rhino-laryngology : official journal of the European Federation of Oto-Rhino-Laryngological Societies. Feb 2015;272(2):497-504.

18. Hassanpour SE, Heidari A, Moosavizadeh SM, Tarahomi MR, Goljanian A, Tavakoli S. Comparison of aesthetic and functional outcomes of spreader graft and autospreader flap in rhinoplasty. World journal of plastic surgery. 2016;5(2):133.
19. Saedi B, Amali A, Gharavis V, Yekta BG, Most SP. Spreader flaps do not change early functional outcomes in reduction rhinoplasty: a randomized control trial. American journal of rhinology \& allergy. Jan-Feb 2014;28(1):70-74.

20. Boccieri A, Macro C, Pascali M. The use of spreader grafts in primary rhinoplasty. Annals of plastic surgery. 2005;55(2):127-131.

21. Murrell GL. Correlation between subjective and objective results in nasal surgery. Aesthetic surgery journal. Feb 2014;34(2):249-257. 